\title{
COMO OS TRIBUNAIS SUPERIORES BRASILEIROS OPERACIONALIZAM A APLICAÇÃO DA VEDAÇÃO DO RETROCESSO NO DIREITO AMBIENTAL? UMA ANÁLISE DO CASO CITY LAPA, JULGADO PELO SUPERIOR TRIBUNAL DE JUSTIÇA
}

\author{
HOW HAVE BRAZILIAN HIGHER COURTS BEEN \\ ENFORCING THE PROHIBITION OF RETROGRESSION IN \\ ENVIRONMENTAL LAW? AN ANALYSIS OF THE CITY LAPA \\ CASE, DECIDED BY THE SUPERIOR COURT OF JUSTICE
}

JULIA DE LAMARE ${ }^{1}$

\begin{abstract}
RESUMO: A operacionalização da ideia de "vedação do retrocesso" na seara do meio ambiente apresenta alguns complicadores. Um deles é o constante conflito existente entre o direito ambiental e outros direitos fundamentais, que também estão protegidos pela obrigação de não retroceder. Ainda, o mencionado instituto se apresenta como um limite adicional à liberdade do legislador, que já se encontra limitado pela própria existência do direito ambiental. Nesse contexto, verifica-se grande dificuldade de determinar de qual retrocesso se está tratando, como ele deve ser identificado, quais são os critérios objetivos capazes de medi-lo e como deve se dar sua operacionalização sem que o princípio democrático seja violado. Uma análise do caso City Lapa - único caso julgado por uma corte superior brasileira no qual há expressa aplicação da vedação do retrocesso ao direito ambiental - e uma reconstrução da doutrina sobre o tema revelam que juristas e tribunais não enxergam o principal problema decorrente da vedação do retrocesso ambiental, tampouco identificam as dificuldades de sua operacionalização.

PALAVRAS-CHAVE: Vedação do Retrocesso Ambiental; Conflito entre Direitos Fundamentais; Princípio Democrático; Operacionalização.
\end{abstract}

ABSTRACT: The use of the prohibition of retrogression idea in environmental law presents some complicate issues. One of them is the constant conflict between environmental law and other fundamental rights, which are also protected by the obligation of no regression. Furthermore, the mentioned idea is an additional limitation to the legislator freedom, which is already limited by the existence of the

Comentário de Jurisprudência recebido em 09.03.2014. Comentário de Jurisprudência aceito para publicação em 07.04.2014.

${ }^{1}$ Mestranda em Direito da Regulação pela FGV Direito Rio.ju_delamare@hotmail.com 
environmental law. In this context, it is very difficult to determine which regression one is dealing with, how it should be identified, what are the objective criteria able to measure it, and how should be it operationalization without violating the democratic principle. An analysis of the City Lapa case - the only one decided by a Brazilian superior court explicitly mentioning the prohibition of retrogression to the environmental law - and a reconstruction of the doctrine dealing with the issue reveal that legal scholars and courts have failed not only to identify the major problem with the prohibition of retrogression enforcement in environmental law, but also to identify the difficulties in its operationalization.

KEYWORDS: Environmental Prohibition of Retrogression; Conflict between Fundamental Rights; Democratic Principle; Operationalization.

SUMÁRIO: Introdução; 1. Breve Resumo do caso City Lapa; 2. Considerações acerca da Vedação do Retrocesso Ambiental; Conclusão; Referências Bibliográficas.

SUMMARY: Introduction; 1. Brief Summary of the City Lapa Case; 2. Considerations Concerning the Environmental Prohibition of Retrogression; Conclusion; References.

\section{INTRODUÇÃO}

A vedação do retrocesso não está expressamente positivada no sistema jurídico constitucional. Sua existência e aplicação são antes de tudo construções da doutrina e da jurisprudência, e não obra direta do constituinte ${ }^{2}$. Essa empreitada interpretativa dos operadores do direito se justifica pelo objetivo a que se propõe: garantir a máxima efetividade dos direitos fundamentais e da Constituição.

A obrigação de não retroceder encerra a ideia de que, ao avançar na concretização de direitos fundamentais, o legislador se vincula ao que foi garantido, de sorte que não Ihe é permitido, a partir daí, recuar na tutela já oferecida, concedendo aos indivíduos menos proteção do que desfrutem até então. Enquanto atributo típico do regime jurídico dos direitos fundamentais, a vedação do retrocesso aplica-se à tutela do meio ambiente ${ }^{3}$, incorporado ao núcleo de proteção humana pelos direitos de terceira geração ${ }^{4}$.

\footnotetext{
${ }^{2}$ BARROSO, Luís Roberto. O Direito Constitucional e a Efetividade de suas Normas: limites e possibilidades da Constituição Brasileira. 5. ed., Rio de Janeiro: Renovar 2001, p. 158.

${ }^{3}$ Ver, e.g., PRIEUR, Michel. De l'urgente nécessité de reconnaitre le principe de "non régression" en droit de l'environnement. Disponível em: http://heinonline.org/HOL/LandingPage?collection= journals\&handle=hein.journals/romjoenl2010\&div=23\&id=\&page=. Último acesso em 05 mar. 2014; BENJAMIN, Antonio Herman. Princípio da Proibição de Retrocesso Ambiental. In: Senado Federal. Princípio da Proibição de Retrocesso Ambiental. Comissão de Meio Ambiente, Defesa do Consumidor e Fiscalização e Controle. Brasília, 2011, p. 55-72. Disponível em: http://www2.senado.gov.br/ bdsf/bitstream/id/242559/1/000940398.pdf. Último acesso em 05 mar. 2014; MOLINARO, Carlos Alberto. Direito Ambiental: proibição de retrocesso. Porto Alegre: Livraria do Advogado Editora, 2007; e SARLET, Ingo Wolfgang; FENSTERSEIFER, Tiago. Direito Constitucional Ambiental: estudos sobre a Constituição, os direitos fundamentais e a proteção do meio ambiente. São Paulo: Editora Revista dos Tribunais, 2011.

${ }^{4}$ Tradicionalmente, a teoria dos direitos fundamentais reconhece a existência de três categorias denominadas de gerações ou dimensões de direitos fundamentais. A primeira geração cuida dos direitos civis e políticos, cuja concretização não depende de uma ação positiva do Estado (e.g. vida, liberdade, propriedade, igualdade e voto). Os direitos de segunda geração, por sua vez,
} 
Em âmbito internacional, um dos mais renomados autores sobre o assunto é Michel Prieur, professor emérito da Universidade de Limoges, na França. Para o mestre francês, a garantia do direito adquirido, na seara ambiental, representa uma porta aberta ao retrocesso capaz de prejudicar as gerações presentes e futuras, contrariando o principal objetivo do direito ambiental, qual seja, o de contribuir para a diminuição da poluição e para a preservação da diversidade biológica ${ }^{5}$. Para ele, "o retrocesso em matéria ambiental não é imaginável"6.

Michel Prieur explica que a vedação do retrocesso, além de ser um princípio, representa um verdadeiro dever de não-regressão para a Administração Pública. Por isso, uma fórmula positiva como "princípio de progressão" não teria sido escolhida de maneira proposital por dois motivos: é muito vaga e pode se aplicar a qualquer norma enquanto instrumento. A expressão "nãoregressão" na seara do meio ambiente significa, para Prieur, "que há distintos graus de proteção ambiental e que os avanços da legislação consistem em garantir, progressivamente, uma proteção a mais elevada possível, no interesse

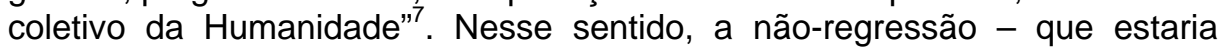
ao lado de princípios do direito ambiental tais como prevenção, precaução, poluidor-pagador e participação do público - é fundamentada em três principais elementos: (i) a própria finalidade do direito ambiental, (ii) a necessidade de se afastar o princípio da mutabilidade do direito e (iii) a intangibilidade dos direitos humanos.

Em solo nacional, também é possível encontrar o entendimento de que a vedação do retrocesso é aplicável ao direito ambiental. Cite-se, a título exemplificativo, Carlos Alberto Molinaro, para quem o mencionado instituto

\footnotetext{
são os chamados direitos econômicos, sociais e culturais e exigem uma atuação positiva do Estado para que sua efetivação seja realmente garantida (e.g. saúde, educação e trabalho). Por fim, os direitos de terceira geração, denominados também de direitos de solidariedade e fraternidade, caracterizam-se como direitos de titularidade coletiva ou difusa (e.g. meio ambiente, autodeterminação dos povos, paz e o desenvolvimento). Há ainda quem enxergue uma quarta dimensão de direitos fundamentais, que seria resultante da globalização desses direitos (e.g. democracia, informação e pluralismo). Cf, nesse sentido, SARLET, Ingo Wolfgang. A Eficácia dos Direitos Fundamentais. 8. ed., rev. atual. Porto Alegre: Livraria do Advogado, 2007, p. 56, e BONAVIDES, Paulo. Curso de Direito Constitucional. 7. ed., São Paulo: Malheiros, 1997, p. 524-526.

${ }^{5}$ PRIEUR, Michel. O Princípio da Proibição de Retrocesso Ambiental. In: Senado Federal. Princípio da Proibição de Retrocesso Ambiental. Comissão de Meio Ambiente, Defesa do Consumidor e Fiscalização e Controle. Brasília, 2011, p. 11-54. Disponível em: http://www2.senado.gov.br/bdsf/ bitstream/id/242559/1/000940398.pdf. Último acesso em 05 mar. 2014.

${ }^{6}$ Tradução livre do original: "Le retour en arribre en matiare d'environnement n'est pas imaginable" cf. PRIEUR, Michel. De l'urgente nécessité de reconnaître le principe de "non régression" en droit de l'environnement. Disponível em: http://heinonline.org/HOL/LandingPage?collection=journals\& handle=hein.journals/romjoenl2010\&div=23\&id=\&page=. Último acesso em 05 mar. 2014.

${ }^{7}$ PRIEUR, Michel. O Princípio da Proibição de Retrocesso Ambiental. In: Senado Federal. Princípio da Proibição de Retrocesso Ambiental. Comissão de Meio Ambiente, Defesa do Consumidor e Fiscalização e Controle. Brasília, 2011, p. 11-54. Disponível em: http://www2.senado.gov.br/bdsf/ bitstream/id/242559/1/000940398.pdf. Último acesso em 05 mar. 2014.
} 
deve ser denominado "proibição da retrogradação socioambiental", pois alega que "retrogradar" expressa melhor a ideia de retroceder, de ir para trás ${ }^{8}$.

Molinaro entende que a proibição da retrogradação socioambiental possui natureza de princípio e encontra fundamento no art. 225, da Constituição Federal de 1988. Para o autor, o referido instituto "está diretamente subsumido no entrelaçamento dos princípios matrizes: dignidade da pessoa humana/ segurança jurídica, ele é condição essencial das condições de responsabilidade socioambiental (...) que deve estar imprimida em todas as relações com o ambiente" .

Em que pesem as considerações acerca da aplicação da não-regressão ao direito ambiental, essa aplicabilidade não é isenta de delicadezas. De fato, a incidência indiscriminada da proibição de retroceder ao direito ambiental possui dois grandes problemas.

Em primeiro lugar, a aplicação irrestrita equivaleria a ignorar completamente a proteção a outros bens jurídicos relevantes de igual estatura constitucional, muitos dos quais também abarcados pela obrigação de não retroceder. Nesse contexto, quanto mais proteção se dá ao direito ambiental, mais se pode restringir, por exemplo, a livre iniciativa, protegida na Constituição Federal de 1988 como um dos fundamentos do Estado Democrático de Direito brasileiro (art. $1^{\circ}, \mathrm{IV}$ ) e considerada também um dos fundamentos da ordem econômica e financeira (art. 170, caput); o direito de propriedade, integrante do rol de direitos fundamentais do art. $5^{\circ}$ da Constituição; e o desenvolvimento do país, um dos objetivos fundamentais da República Federativa do Brasil (art. $3^{\circ}$, II). Além disso, assim como qualquer norma-princípio, a não-regressão das normas ambientais está sujeita a ponderações, sendo de todo incompatível com a própria noção dogmática de princípio o caráter absoluto que lhe é atribuído com frequência pelos juristas e pelos tribunais. Não se pode, portanto, simplesmente maximizar a proteção do meio ambiente sem considerar suas implicações sobre outros interesses constitucionais igualmente relevantes, sob pena de uma concretização apenas parcial da vontade do legislador constituinte.

Em segundo lugar, aplicar de maneira absoluta a ideia de vedação do retrocesso acaba por limitar excessivamente a liberdade de conformação legislativa. E o que é pior: com o passar do tempo, essa dificuldade dá origem a uma tensão intergeracional, na medida em que os representantes do povo de hoje são impedidos de atuar em razão de decisões tomadas décadas atrás. Na seara do meio ambiente, o conflito com o princípio democrático parece ser ainda mais intenso, visto que o direito ambiental já representa, por si só, uma limitação à atuação do legislador. A vedação do retrocesso ambiental seria, assim, uma limitação adicional.

\footnotetext{
${ }^{8}$ MOLINARO, Carlos Alberto. Direito Ambiental: proibição de retrocesso. Porto Alegre: Livraria do Advogado Editora, 2007, p. 67.

${ }^{9}$ Idem, p. 74.
} 
Nesse cenário, surgem alguns questionamentos: o que significa "retrocesso" para fins jurídico-constitucionais? Que indicadores são (ou seriam) capazes de identificá-lo e de medi-lo? Como deve se dar sua operacionalização pelos Tribunais e demais Poderes da República? Faz sentido falar em retrocesso diante de uma sociedade dinâmica e uma Constituição compromissória? A vedação do retrocesso ambiental, como um limite adicional, seria compatível com o princípio democrático?

O presente trabalho tem por finalidade demonstrar, através da análise do caso City Lapa, que a jurisprudência e a doutrina existentes acerca do tema não têm sido capazes de enfrentar os problemas identificados com a objetividade e a consistência que se espera.

\section{BREVE RESUMO DO CASO CITY LAPA}

Pesquisa realizada no Supremo Tribunal Federal ("STF") e no Superior Tribunal de Justiça ("STJ") revelou que é ainda bastante acanhada a aplicação da vedação do retrocesso ambiental na jurisprudência dos tribunais superiores brasileiros. No STF não se encontrou qualquer julgado que aplicasse expressamente o instituto. No STJ, por sua vez, localizou-se um acórdão em que o tema foi endereçado explicitamente: trata-se do Recurso Especial $n^{\circ}$ 302.906 julgado em 26.08.2010, de relatoria do Ministro Herman Benjamin ${ }^{10}$.

O caso versou, na origem, sobre julgamento único, feito pelo Tribunal de Justiça de São Paulo ("TJSP"), de nunciação de obra nova e de ação civil pública que possuíam identidade de partes e identidade entre pedido e causa de pedir: ambas tinham como objetivo a demolição de prédio no Município de São Paulo que não obedecia às restrições convencionais propostas pelo loteador, City Lapa. Tais restrições - todas estabelecidas pelo loteador no plano de loteamento, arquivadas no registro imobiliário e transcritas na escritura de alienação - propunham que a área loteada somente poderia receber edificações unifamiliares, contrastando frontalmente com a pretensão da incorporadora (CCK Construtora e Incorporadora Ltda.) de edificar construção de nove andares. Ocorreu que, posteriormente ao estabelecimento das restrições convencionais pelo loteador, o Município de São Paulo editou a Lei $n^{\circ} 8.001 / 73$, que trazia condicionamentos menos severos do que as restrições convencionais ao direito de construir. Em resumo, a questão central do caso era decidir o que deveria prevalecer: restrições convencionais mais rígidas estabelecidas pelo loteador ou lei municipal mais flexível editada em momento posterior.

\footnotetext{
${ }^{10}$ A pesquisa foi realizada no dia 22 de fevereiro de 2014, nos sítios do Superior Tribunal de Justiça (http://www.stj.jus.br/portal_stj/publicacao/engine.wsp) e do Supremo Tribunal Federal (http://www.stf.jus.br/portal/principal/principal.asp) com os seguintes termos: "não-regressão", "vedação de retrocesso", "proibição de retrocesso", "retrocesso social", "não retorno da concretização", "eficácia vedativa e retrocesso", "eficácia impeditiva e retrocesso", "não evolução reacionária" e "proibição contra revolução". Diante da falta de uniformidade na denominação da vedação do retrocesso, não se descarta a possível existência de acórdãos que trataram do tema utilizando outras expressões. Além disso, não se descarta também que outros acórdãos tenham enfrentado o tema sem, no entanto, nomear o princípio.
} 
Por unanimidade e seguindo o voto do relator Desembargador Oliveira Santos, o TJSP entendeu que, se observada a nova lei municipal, estar-se-ia "ferindo o direito adquirido e até mesmo o ato jurídico perfeito. A lei superveniente estaria ofendendo direito do loteador, dos adquirentes dos lotes, dos vizinhos"11. Ademais, afirmou que a observância às restrições convencionais é garantida pelo art. 39, da Lei Municipal $n^{\circ} 8.001 / 73$, que acolheu a tese da maior restrição: prevalece o que for mais exigente. Nesse sentido, o TJSP deu provimento às ações, determinando que a CCK Construtora e Incorporadora Ltda. demolisse a construção, sob pena de multa.

Inconformada com a decisão, a construtora interpôs recurso especial em face do acórdão proferido pelo TJSP, sob a principal alegação de violação ao direito de propriedade. O Recurso Especial n ${ }^{\circ} 302.906 / S P$ foi conhecido, porém não provido. Confira-se parte da ementa:

PROCESSUAL CIVIL, ADMINISTRATIVO, AMBIENTAL E URBANÍSTICO. LOTEAMENTO CITY LAPA. AÇÃO CIVIL PÚBLICA. AÇÃO DE NUNCIAÇÃO DE OBRA NOVA. RESTRIÇÕES URBANÍSTICOAMBIENTAIS CONVENCIONAIS ESTABELECIDAS PELO LOTEADOR. ESTIPULAÇÃO CONTRATUAL EM FAVOR DE TERCEIRO, DE NATUREZA PROPTER REM. DESCUMPRIMENTO. PRÉDIO DE NOVE ANDARES, EM ÁREA ONDE SÓ SE ADMITEM RESIDÊNCIAS UNI FAMILIARES. PEDIDO DE DEMOLIÇÃO. VÍCIO DE LEGALIDADE E DE LEGITIMIDADE DO ALVARÁ. IUS VARIANDI ATRIBUÍDO AO MUNICÍPIO. INCIDÊNCIA DO PRINCÍPIO DA NÃO-REGRESSÃO (OU DA PROIBIÇÃO DE RETROCESSO) URBANÍSTICO-AMBIENTAL. VIOLAÇÃO AO ART. 26, VII, DA LEI 6.766/79 (LEI LEHMANN), AO ART. 572 DO CÓDIGO CIVIL DE 1916 (ART. 1.299 DO CÓDIGO CIVIL DE 2002) E À LEGISLAÇÃO MUNICIPAL. ART. 334, I, DO CÓDIGO DE PROCESSO CIVIL. VOTO-MÉRITO.

1. As restrições urbanístico-ambientais convencionais, historicamente de pouco uso ou respeito no caos das cidades brasileiras, estão em ascensão, entre nós e no Direito comparado, como veículo de estímulo a um novo consensualismo solidarista, coletivo e intergeracional, tendo por objetivo primário garantir às gerações presentes e futuras espaços de convivência urbana marcados pela qualidade de vida, valor estético, áreas verdes e proteção contra desastres naturais.

2. Nessa renovada dimensão ética, social e jurídica, as restrições urbanístico-ambientais convencionais conformam genuína índole pública, o que lhes confere caráter privado apenas no nome, porquanto não se deve vê-las, de maneira reducionista, tão-só pela ótica do loteador, dos compradores originais, dos contratantes posteriores e dos que venham a ser lindeiros ou vizinhos.

(...) 9. A Administração não fica refém dos acordos "egoísticos" firmados pelos loteadores, pois reserva para si um ius variandi, sob cuja égide as

${ }^{11}$ BRASIL, Tribunal de Justiça de São Paulo, Apelação Cível no 93.607-5/4. Rel. Des. Oliveira Santos, $6^{\text {a }}$ Câmara de Direito Público, julgado em 15.06.1999. 
restrições urbanístico-ambientais podem ser ampliadas ou, excepcionalmente, afrouxadas.

10. O relaxamento, pela via legislativa, das restrições urbanísticoambientais convencionais, permitido na esteira do ius variandi de que é titular o Poder Público, demanda, por ser absolutamente fora do comum, ampla e forte motivação lastreada em clamoroso interesse público, postura incompatível com a submissão do Administrador a necessidades casuísticas de momento, interesses especulativos ou vantagens comerciais dos agentes econômicos.

11. O exercício do ius variandi, para flexibilizar restrições urbanísticoambientais contratuais, haverá de respeitar o ato jurídico perfeito e o licenciamento do empreendimento, pressuposto geral que, no Direito Urbanístico, como no Direito Ambiental, é decorrência da crescente escassez de espaços verdes e dilapidação da qualidade de vida nas cidades. Por isso mesmo, submete-se ao princípio da não-regressão (ou, por outra terminologia, princípio da proibição de retrocesso), garantia de que os avanços urbanístico-ambientais conquistados no passado não serão diluídos, destruídos ou negados pela geração atual ou pelas seguintes.

(...) 19. Recurso Especial não provido. $^{12}$

\section{CONSIDERAÇÕES ACERCA DA VEDAÇÃO DO RETROCESSO AMBIENTAL}

Em seu voto, o relator Ministro Herman Benjamin, entre outros argumentos, defendeu que, como regra geral, o Estado não está autorizado a flexibilizar restrições urbanístico-ambientais convencionais; isto só seria possível na presença de inequívoco interesse público, incapaz de ser atendido por outra via ou mecanismo menos gravoso à coletividade de vizinhos (grifou-se)". Segundo seu entendimento, tal regra se submete ao princípio da nãoregressão, traduzido na "garantia de que os avanços urbanístico-ambientais conquistados no passado não serão destruídos ou negados pela geração atual". Nesse sentido, Herman Benjamin entendeu que o legislador poderia abrandar as exigências urbanístico-ambientais convencionais apenas em circunstâncias excepcionais e de maneira cabalmente motivada.

O Ministro relator não pareceu, em momento algum, preocupado com as peculiaridades do caso concreto, tais como a real capacidade de as restrições propostas pelo loteador protegerem, de fato, o direito urbanístico e o direito ambiental e se sua manutenção ainda faria sentido nos dias atuais. Limitou-se a definir que tais restrições representam avanço na proteção urbanísticoambiental e, como tal, não poderiam sofrer alterações - nunca e em quaisquer que sejam as circunstâncias. Ignorou-se, por completo, a possibilidade de mutação do direito.

\footnotetext{
${ }^{12}$ BRASIL, Superior Tribunal de Justiça, REsp. 302.906/SP. Rel. Min. Herman Benjamin, Segunda Turma, julgado em 26.08.2010. Grifou-se.
} 
Talvez o direito ambiental, por sua natureza de direito fundamental e, portanto, por sua enorme importância, seja menos tolerante a mudanças. No entanto, negar a possibilidade de mutação é o mesmo que negar, por exemplo, que novas tecnologias podem ser desenvolvidas e, assim, formas pretéritas de proteções ao direito ambiental deixem de fazer sentido nos dias de hoje. Nesse caso, não poderia o legislador revogar uma norma que trouxe instrumentos de proteção ao meio ambiente no passado que não mais sejam adequados atualmente? Veja-se exemplo trazido por Michel Prieur:

as descobertas científicas, graças à pesquisa estimulada pelo princípio de precaução, assim como as melhorias aportadas ao meio ambiente, podem conduzir à supressão da proteção que não seja mais útil ao meio ambiente, como é o exemplo a supressão da inscrição de uma espécie na lista daquelas ameaçadas de extinção por haver-se reconstituído na natureza. Os progressos contínuos do Direito Ambiental, vinculados aos progressos da ciência e da tecnologia, fazem com que os limites de não regressão estejam em constante mutação ${ }^{13}$.

Verifica-se que o referido autor trouxe um limite concreto à incidência da vedação do retrocesso: quando se tratar de proteção ambiental que não mais possui sentido na realidade, graças à evolução tecnológica, o legislador pode revogá-la ou substitui-la sem que incorra em retrocesso ambiental.

O mesmo cuidado, no entanto, não foi tomado por Herman Benjamin, que ao afirmar que "essas alterações legislativas [que diminuem restrições já conquistadas] (...) se submetem rigorosamente ao princípio da não-regressão", parece defender uma aplicação irrestrita do instituto. No seu voto, o Ministro do STJ afirmou apenas que o Estado pode fazer alterações reducionistas na legislação ambiental, sem incorrer em violação ao dever de não regressão, desde que diante de interesse público relevante, de circunstâncias excepcionais ou de motivos determinantes para "dar marcha a ré nos mecanismos de proteção urbanística e ambiental".

Veja-se que Herman Benjamin se utiliza de conceitos muito vagos e amplos quando se refere aos limites da vedação do retrocesso ambiental, como "interesse público", "circunstâncias excepcionais" e "motivos determinantes". Por isso, para tentar tornar mais concreto o referido princípio, esboçou um elenco de motivos determinantes e circunstâncias especiais que legitimariam o Estado a eliminar ou a suavizar as restrições urbanístico-ambientais convencionais. São eles: (i) "quando o caráter do próprio direito de propriedade passa por insuperável e irreversível transformação"; (ii) quando "o aspecto ou função do bairro ou local de incidência das restrições urbanístico-ambientais

\footnotetext{
${ }^{13}$ PRIEUR, Michel. O Princípio da Proibição de Retrocesso Ambiental. In: Senado Federal. Princípio da Proibição de Retrocesso Ambiental. Comissão de Meio Ambiente, Defesa do Consumidor e Fiscalização e Controle. Brasília, 2011, p. 11-54. Disponível em: http://www2.senado.gov.br/bdsf/ bitstream/id/242559/1/000940398.pdf. Último acesso em 05 mar. 2014.
} 
converte-se, de maneira avassaladora e incontornável, em algo completamente distinto daquele que justificou, dezenas de anos atrás, a imposição de rígidos controles sobre o direito de construir"; e (iii) quando da ocorrência do "obsoletismo valorativo e do obsoletismo técnico", definido por Herman Benjamin como um "envelhecimento que não surge em razão de norma ou lei que lhe é posterior", mas em decorrência de transformações dos valores e expectativas ético-sociais ou por conta do avanço do conhecimento científico.

É de se destacar a atitude do Ministro do STJ, que se preocupou em elencar as situações que justificariam mitigação ou eliminação de garantias já existentes. Não obstante, não tratou do "relevante interesse público", apontado como capaz de autorizar o Estado a flexibilizar determinados patamares de proteção. Vê-se, pois, que conceitos vagos e subjetivos ainda permeiam a aplicação da vedação do retrocesso ambiental.

A falta de objetividade não é registrada apenas na jurisprudência. $\mathrm{Na}$ doutrina, muitos autores trazem conceitos incertos e indefinidos ao tratar da obrigação de não retroceder à proteção do meio ambiente. Ingo Sarlet e Tiago Fensterseifer defendem que existe um patamar mínimo de tutela ambiental, aquém do qual não podem ficar as novas legislações, sob pena de violação ao retrocesso ambiental. Tal patamar teria como referência a noção de mínimo existencial, que vem a significar "o conjunto de prestações materiais que asseguram a cada indivíduo uma vida digna, no sentido de uma vida saudável, ou seja, de uma vida que corresponda a padrões qualitativos mínimos"14.

O conceito de mínimo existencial é por demais vago: quais são as prestações que asseguram a cada indivíduo uma vida digna? O que é uma vida digna e quais são os padrões qualitativos mínimos que a definem como tal?

É possível encontrar também uma correlação entre vedação do retrocesso ambiental e mínimo existencial na obra de Patryck de Araújo Ayala. Para o autor, a proibição de retrocesso não pode ser vista como um princípio geral, pois diz respeito somente à garantia de que o mínimo concretizado não possa ser revisto. A seu ver, "é somente este mínimo que se encontraria sob a reserva de revisão pelas decisões estatais"15. E para tentar dar concretude ao seu argumento traz a seguinte definição:

uma referência possível para desenvolver a noção de um mínimo de conteúdo ambiental (mínimo de existência ecológica) pode ser associada à suficiente qualidade de vida enquanto resultado de uma leitura de

\footnotetext{
${ }^{14}$ SARLET, Ingo Wolfgang; FENSTERSEIFER, Tiago. Direito Constitucional Ambiental: estudos sobre a Constituição, os direitos fundamentais e a proteção do meio ambiente. São Paulo: Editora Revista dos Tribunais, 2011, p. 206.

${ }^{15}$ AYALA, Patryck de Araújo. Direito Fundamental ao Ambiente, Mínimo Existencial Ecológico e Proibição de Retrocesso na Ordem Constitucional Brasileira. In: Revista dos Tribunais, $99^{\circ}$ ano, vol. 901 , nov. 2010 , p. 29-64.
} 
dignidade compreendida como a manifestação de diversas posições jurídicas fundamentais de um direito fundamental como um todo: funções defensiva e prestacional do direito fundamental ao meio ambiente, além de também ser o resultado de uma tarefa estatal ${ }^{16}$.

É este mínimo, dificilmente identificado em um caso concreto, que possui uma blindagem em relação às iniciativas revisoras do Poder Legislativo. Em que medida referida definição pode auxiliar na operacionalização da vedação do retrocesso na seara do meio ambiente? Aqui, incidem as mesmas considerações feitas sobre o conceito de mínimo existencial abordado por Ingo Sarlet e Tiago Fensterseifer feitas acima.

Destaca-se, ainda, que Ayala tentou trazer objetividade a não-regressão ambiental. O autor defende que uma abordagem sobre a noção ecológica do princípio da vedação do retrocesso deve vir acompanhada (I) do objeto do qual se ocupa o princípio e (ii) da demonstração de uma situação objetiva de retrocesso. Em relação ao primeiro tópico, afirma que o objeto da proteção são as realidades normativas, não podendo haver um agravamento da situação ecológica já positivada. No que tange ao segundo, entende que:

uma norma deve ser considerada regressiva sempre que o grau de efetividade de um direito veiculado pela nova norma resulte inferior àquele que já havia sido alcançado anteriormente, de modo que somente seria possível afirmar-se uma situação de reversão proibida ou de retrocesso proibido mediante uma análise empírica e comparativa entre as realidades normativas ${ }^{17}$.

Patryck Ayala explica, assim, que a demonstração do retrocesso em uma situação objetiva depende de uma análise empírica e comparativa. Contudo, isso pouco contribui para responder as perguntas levantadas no início desse trabalho.

A pouca objetividade na definição dos parâmetros de aplicação da vedação do retrocesso ambiental é, por si só, um grave problema, visto que ameaça a efetividade de sua operacionalização. No entanto, a presença de critérios vagos e indefinidos, somada ao caráter absoluto que parece se querer emprestar à vedação do retrocesso ambiental, torna-se ainda mais grave quando se tem em mente que o mencionado instituto pretende impedir, em algumas situações, a atuação do legislador. Herman Benjamin não tratou desse aspecto em seu voto no caso City Lapa. No entanto, em obra doutrinária acerca do tema afirma que não se pode atribuir à não-regressão um caráter absoluto, pois seria um exagero vedar por completo a liberdade do legislador

\footnotetext{
${ }^{16}$ AYALA, Patryck de Araújo. Devido Processo Ambiental e o Direito Fundamental ao Meio Ambiente. Rio de Janeiro: Lumen Juris, 2011, p. 182.

${ }^{17}$ AYALA, Patryck de Araújo. Direito Fundamental ao Ambiente, Mínimo Existencial Ecológico e Proibição de Retrocesso na Ordem Constitucional Brasileira. In: Revista dos Tribunais, $99^{\circ}$ ano, vol. 901 , nov. 2010 , p. 29-64.
} 
de rever as leis, assim como admitir sua liberdade irrestrita. Neste contexto, afirma que "o princípio da proibição do retrocesso não institui camisa de força ao legislador e ao implementador, mas impõe-Ihes limites não discricionários à sua atuação"18.

Ocorre que o problema prático é justamente estabelecer quais são esses limites não discricionários à atuação do legislador, até porque a própria existência do direito constitucional ambiental já é, em si, uma limitação à atuação do Poder Legislativo. Permanece, assim, a pergunta: a vedação do retrocesso ambiental, como um limite adicional, seria compatível com o princípio democrático?

Nesse ponto, merece destaque posicionamento de Ingo Sarlet e Tiago Fensterseifer que enxergam nova dimensão da vedação de retrocesso. Para os autores, o Estado não só não pode editar novas normas que enfraqueçam patamares de proteção já garantidos, como também possui a obrigação de avançar na proteção dos direitos econômicos, sociais e culturais ${ }^{19} . \mathrm{O}$ argumento traz nova fundamentação jurídica à proibição de retrocesso: a cláusula de progressividade ou o dever de progressiva realização previstos no Pacto Internacional de Direitos Econômicos, Sociais e Culturais ${ }^{20}$ e na Convenção Americana de Direitos Humanos ${ }^{21}$. Segundo Ingo Sarlet e Tiago Fensterseifer, progresso deve ser compreendido como um dever de desenvolvimento sustentável. Confiram-se as suas palavras:

a garantia constitucional da proibição de retrocesso contempla dois conteúdos normativos que se complementam: se, por um lado, impõe-se ao Estado a obrigação de "não piorar" as condições normativas hoje existentes em determinado ordenamento jurídico (...), por outro lado, também se faz imperativo, especialmente relevante no contexto da

${ }^{18}$ BENJAMIN, Antonio Herman. Princípio da Proibição de Retrocesso Ambiental. In: Senado Federal. Princípio da Proibição de Retrocesso Ambiental. Comissão de Meio Ambiente, Defesa do Consumidor e Fiscalização e Controle. Brasília, 2011, p. 55-72. Disponível em: http://www2. senado.gov.br/bdsf/bitstream/id/242559/1/000940398.pdf. Último acesso em 05 mar. 2014.

${ }^{19}$ SARLET, Ingo Wolfgang; FENSTERSEIFER, Tiago. Direito Constitucional Ambiental: estudos sobre a Constituição, os direitos fundamentais e a proteção do meio ambiente. São Paulo: Editora Revista dos Tribunais, 2011, p. 197.

${ }^{20}$ Pacto Internacional dos Direitos Econômicos, Sociais e Culturais de 1966 , art. $2^{\circ}$, parágrafo $1^{\circ}$ : Cada Estado Membro no presente Pacto compromete-se a adotar medidas, tanto por esforço próprio como pela assistência e cooperação internacionais, principalmente nos planos econômico e técnico, até o máximo de seus recursos disponíveis, que visem a assegurar, progressivamente, por todos os meios apropriados, o pleno exercício dos direitos reconhecidos no presente Pacto, incluindo, em particular, a adoção de medidas legislativas.

${ }^{21}$ Convenção Americana de Direitos Humanos, art. 26: Desenvolvimento progressivo: Os Estadospartes comprometem-se a adotar as providências, tanto no âmbito interno, como mediante cooperação internacional, especialmente econômica e técnica, a fim de conseguir progressivamente a plena efetividade dos direitos que decorrem das normas econômicas, sociais e sobre educação, ciência e cultura, constantes da Carta da Organização dos Estados Americanos, reformada pelo Protocolo de Buenos Aires, na medida dos recursos disponíveis, por via legislativa ou por outros meios apropriados. 
proteção do ambiente, uma obrigação de "melhorar", ou seja, de aprimorar tais condições normativas - e também fáticas - no sentido de assegurar um contexto cada vez mais favorável ao desfrute de uma vida digna e saudável pelo indivíduo e pela coletividade como um todo ${ }^{22}$.

Essa nova dimensão da obrigação de não retroceder deveria vir acompanhada também de critérios objetivos capazes de definir em que situações o Estado deve avançar na proteção ambiental. Caso contrário, mais uma vez a liberdade de conformação legislativa será ofendida, o que, por conseguinte, viola o princípio democrático.

No caso ora analisado, sob a alegação de que o Estado não pode retroceder em patamares de proteção já garantidos, e entre outros argumentos, o Ministro Herman Benjamin entendeu que as restrições convencionais propostas pelo loteador deveriam prevalecer sobre a lei municipal menos restritiva. Foi nos termos acima expostos que, pela primeira vez, um tribunal superior brasileiro aplicou expressamente a vedação do retrocesso ao direito do meio ambiente.

O julgado City Lapa, embora pioneiro na aplicação da não-regressão ambiental, não apresenta solução aos problemas identificados. Como se viu, nem na doutrina foi possível extrair critérios objetivos capazes de identificar as situações nas quais, de fato, haverá retrocesso na proteção ambiental. Também não foi possível definir qual retrocesso deve prevalecer quando dois direitos fundamentais estão em colisão (in casu, o direito ao meio ambiente e o direito de propriedade), tampouco se enfrentou o problema da legitimidade democrática que, como apontado, é ainda mais sensível no direito ambiental.

\section{CONCLUSÃO}

Neste breve trabalho foi possível verificar que a ideia de vedação do retrocesso, quando aplicada ao direito ambiental, apresenta algumas dificuldades que the são peculiares. Com efeito, na esfera do meio ambiente há um constante conflito existente entre diversos direitos fundamentais, todos abarcados pela obrigação de não retroceder. Ademais, a não-regressão se apresenta como uma restrição adicional à liberdade de conformação legislativa, visto que o legislador já está limitado pela própria existência do direito ambiental.

Diante desse cenário, surgem alguns questionamentos: falar em "retrocesso" é falar em qual retrocesso? Quais são os indicadores capazes de identificar e medir o retrocesso? Como deve se dar sua operacionalização? A vedação do retrocesso ambiental, como um limite adicional, seria compatível com o princípio democrático?

\footnotetext{
${ }^{22}$ SARLET, Ingo Wolfgang; FENSTERSEIFER, Tiago. Direito Constitucional Ambiental: estudos sobre a Constituição, os direitos fundamentais e a proteção do meio ambiente. São Paulo: Editora Revista dos Tribunais, 2011, p. 197.
} 
A partir da análise do caso City Lapa e de um apanhado da doutrina acerca da vedação do retrocesso ambiental, constatou-se que os juristas e os tribunais tendem a não enxergar essas questões. A preocupação tem sido direcionada apenas ao retrocesso no meio ambiente, sem perceber a possibilidade de restrições recíprocas quando do conflito entre direitos fundamentais. Além disso, parece não se atentar à possibilidade de violação ao princípio democrático. É necessário, portanto, pensar em uma operacionalização da vedação do retrocesso ambiental que, ao mesmo tempo em que seja eficiente, tente absorver todos os direitos e princípios em colisão ${ }^{23}$.

\section{REFERÊNCIAS BIBLIOGRÁFICAS}

AYALA, Patryck de Araújo. Direito Fundamental ao Ambiente, Mínimo Existencial Ecológico e Proibição de Retrocesso na Ordem Constitucional Brasileira. In: Revista dos Tribunais, $99^{\circ}$ ano, vol. 901, nov. 2010.

AYALA, Patryck de Araújo. Devido Processo Ambiental e o Direito Fundamental ao Meio Ambiente. Rio de Janeiro: Lumen Juris, 2011.

BARROSO, Luís Roberto. O Direito Constitucional e a Efetividade de suas Normas: limites e possibilidades da Constituição brasileira. 5. ed., Rio de Janeiro: Renovar 2001.

BENJAMIN, Antonio Herman. Princípio da Proibição de Retrocesso Ambiental. In: Senado Federal. Princípio da Proibição de Retrocesso Ambiental. Comissão de Meio Ambiente, Defesa do Consumidor e Fiscalização e Controle. Brasília, 2011, p. 55-72. Disponível em: http://www2.senado.gov.br/bdsf/bitstream/id/242559/1/000940398.pdf. Último acesso em 05 mar. 2014.

BONAVIDES, Paulo. Curso de Direito Constitucional. 7. ed., São Paulo: Malheiros, 1997. BRASIL, Superior Tribunal de Justiça, Resp. 302.906/SP. Rel. Min. Herman Benjamin, Segunda Turma, julgado em 26.08.2010.

BRASIL, Tribunal de Justiça de São Paulo, Apelação Cível no 93.607-5/4. Rel. Des. Oliveira Santos, 6a Câmara de Direito Público, julgado em 15.06.1999.

DE LAMARE, Julia. A Proibição do Retrocesso no Direito Ambiental: avanço para onde? In Coleção Jovem Jurista. Rio de Janeiro, Escola de Direito FGV Direito Rio, 2013, p. 137-186.

MOLINARO, Carlos Alberto. Direito Ambiental: proibição de retrocesso. Porto Alegre: Livraria do Advogado Editora, 2007.

PIOVESAN, Flávia. Direitos Humanos e o Direito Constitucional Internacional. 8. ed., São Paulo: Saraiva, 2007, p. 178 apud SARLET, Ingo Wolfgang; FENSTERSEIFER, Tiago. Direito Constitucional Ambiental: estudos sobre a Constituição, os direitos fundamentais e a proteção do meio ambiente. São Paulo: Editora Revista dos Tribunais, 2011.

PRIEUR, Michel. De l'urgente nécessité de reconnaître le principe de "non régression" en droit de l'environnement. Disponível em: http://heinonline.org/HOL/LandingPage? collection=journals\&handle=hein.journals/romjoenl2010\&div=23\&id=\&page=. Último acesso em 05 mar. 2014.

\footnotetext{
${ }^{23}$ Para uma tentativa inicial de resposta a essas questões, ver: DE LAMARE, Julia. A Proibição do Retrocesso no Direito Ambiental: avanço para onde? In Coleção Jovem Jurista. Rio de Janeiro, Escola de Direito FGV Direito Rio, 2013, p. 137-186.
} 
PRIEUR, Michel. O Princípio da Proibição de Retrocesso Ambiental. In: Senado Federal. Princípio da Proibição de Retrocesso Ambiental. Comissão de Meio Ambiente, Defesa do Consumidor e Fiscalização e Controle. Brasília, 2011, p. 11-54. Disponível em: http://www2.senado.gov.br/bdsf/bitstream/id/242559/1/000940398.pdf. Último acesso em 05 mar. 2014.

SARLET, Ingo Wolfgang. A Eficácia dos Direitos Fundamentais. 8. ed., rev. atual. Porto Alegre: Livraria do Advogado, 2007.

SARLET, Ingo Wolfgang; FENSTERSEIFER, Tiago. Direito Constitucional Ambiental: estudos sobre a Constituição, os direitos fundamentais e a proteção do meio ambiente. São Paulo: Editora Revista dos Tribunais, 2011. 